\title{
Diffusion-controlled growth and degree of disequilibrium of garnet porphyroblasts: is diffusion-controlled growth of porphyroblasts common?
}

\author{
Kazuhiro Miyazaki
}

\begin{abstract}
Rate-limiting processes and the degree of disequilibrium during metamorphic mineral growth are key controls on the rate of dehydration and hydration in the Earth's crust. This paper examines diffusion-controlled growth and the degree of disequilibrium of garnet porphyroblasts in the Tsukuba metamorphic rocks of central Japan. The analyzed porphyroblasts have irregular and branching morphologies with clear diffusional haloes, indicating that they grew in a diffusion-controlled regime. Mathematical analysis shows that the dominant wavelength of the interface of a garnet porphyroblast is dependent on the extent of supersaturation $(\Delta \zeta)$, which is an index for the degree of disequilibrium. Using the calculated upper and lower limits of the dominant wavelength, the value of $\Delta \zeta$ is estimated to be $0.05 \times 10^{-1}-0.16$, which corresponds to a Gibbs free energy $\left(\Delta G_{r}\right)$ overstep of $0.9-27 \mathrm{~kJ}$ per mole of garnet (12 oxygen atoms) and a temperature overstep $(\Delta T)$ of $1.7-50^{\circ} \mathrm{C}$. Using the average value of the dominant wavelength, the following results are obtained: $\Delta \zeta=0.15 \times 10^{-1}, \Delta G_{r}=2.7 \mathrm{~kJ}$ per mole of garnet, and $\Delta T=5^{\circ} \mathrm{C}$. These values bring into question the importance of diffusion-controlled growth of garnet porphyroblasts, as highly irregular and branching garnet porphyroblasts are rare in most metamorphic belts. After significant overstepping for the nucleation of garnet, the garnet porphyroblasts grow at a high degree of disequilibrium. However, a high degree of disequilibrium under diffusion-controlled growth would be characterized by diffusional instability. The results indicate that garnet porphyroblasts that lack an irregular and branching morphology may grow at a high degree of disequilibrium under interface-controlled growth, provided they are set in a medium where the diffusion and supply of constituent elements are sufficient, such as a sufficient volume of metamorphic fluid.
\end{abstract}

Keywords: Diffusion-controlled growth; Garnet; Metamorphism; Disequilibrium; Porphyroblast

\section{Background}

Rate-limiting processes and the degree of disequilibrium of a metamorphic reaction are crucial factors in the devolatilization and/or hydration of the Earth's crust. The release and consumption of fluids, such as water-rich fluids and melts, have a critical influence on the evolution of mountain building and the transport of energy and materials in the crust. Many studies have assessed the rate-limiting processes for metamorphic reactions (e.g., Ague and Carlson 2013, Walther and Wood 1984). The following three types of

Correspondence: kazu-miyazaki@aist.go.jp

Geological Survey of Japan, AIST, Higashi 1-1-1, Tsukuba, 305-8567 Ibaraki, Japan 1978): 1) interface-controlled, 2) diffusion-controlled, and 3) heat-flow-controlled. The formation of garnet is one of the most common devolatilization reactions in the crust (e.g., Ague and Carlson 2013), and diffusion-controlled processes are widely applied to garnet-forming reactions, including the nucleation and growth of the garnet (e.g., Carlson 1989) and Ostwald ripening (Miyazaki 1991, 1996). Although Carlson (1989) and Miyazaki (1991) both assumed a diffusion-controlled process, the degree of disequilibrium differed in their models. In particular, the degree of disequilibrium for the nucleation and growth model is much higher than that for Ostwald ripening. 
Even if the rate-limiting processes were governed by diffusion, the degree of disequilibrium should directly affect the reaction rate and the patterns of metamorphic textures. The growth of a metamorphic mineral at a low degree of disequilibrium (i.e., a system close to equilibrium, implying a small overstep from the equilibrium temperature and a low degree of supersaturation for the metamorphic reaction) may result in an equigranular metamorphic texture because interfacial energy becomes an important control on crystal morphology and size. On the other hand, growth at a high degree of disequilibrium with a limited number of nuclei may result in a porphyroblastic texture. However, diffusion-controlled growth of a mineral at a high degree of disequilibrium is likely to involve diffusional instability and may lead to highly irregular and branched morphologies. In this paper, I examine the diffusional instability of garnet porphyroblasts (Tsukuba metamorphic rocks, central Japan) that grew in a diffusion-controlled regime.

\section{Methods}

\section{Identification of a texture characteristic of diffusion-} controlled growth

Diffusion-controlled growth is the result of the sluggish diffusion of the elements required for growth of the product of the reaction and is characterized by the presence of a depleted zone that formed around the growing product (Fig. 1). It is assumed that a uniform medium existed initially before nucleation of the product. After nucleation occurs, the region surrounding the reaction product will supply elements to the growing product. Although a uniform medium continues to exist outside the region immediately surrounding the growing product, the concentration of elements required for growth is reduced in the immediate surroundings by the diffusion of those elements to the product. If the reactants needed for the growth of the product exist in the surrounding region, they should dissolve selectively. Therefore, it is expected that the reactants should be remarkably depleted in the immediate surroundings of the growing product. The resulting depletion zone contains the characteristic texture for diffusion-controlled growth. Therefore, a search for a zone that is depleted in the reactants of a garnet-forming reaction is the first step towards estimating the degree of disequilibrium associated with diffusion-controlled growth of garnet porphyroblasts.

\section{Mathematical analysis of diffusional instability}

Diffusional instability should occur when a product grows by a diffusion-controlled process. For example, if the small tip of a growing product occurs in a diffusional medium, the concentration gradient around the tip becomes larger compared with the area around the flat surface of the product (Fig. 2). The growth rate of the tip will be higher than the flat surface because the influx of any reaction-limiting

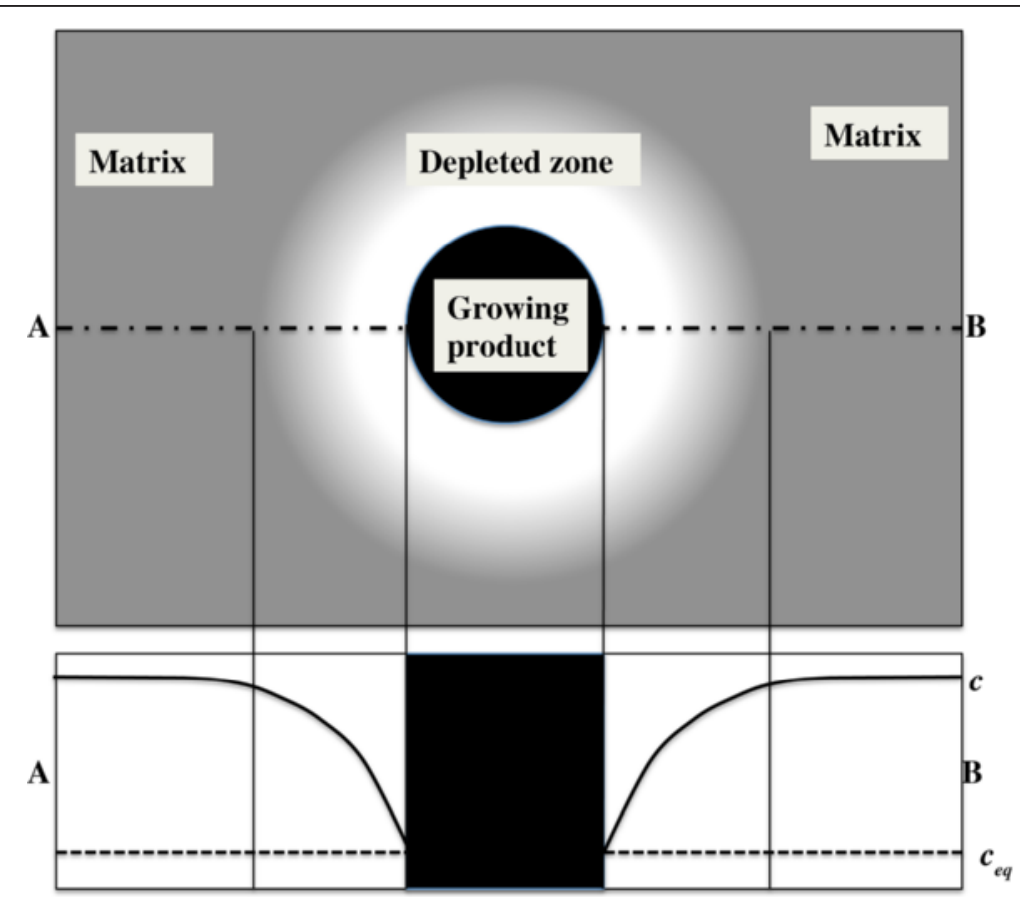

Fig. 1 Schematic diagram of diffusion-controlled growth. A zone depleted in the reaction-limiting component (RLC) should form around the growing product in a diffusion-controlled regime. The terms $c$ and $c_{e q}$ represent the concentrations of the RLC in the diffusional medium and at the flat surface interface of the growing product, respectively 


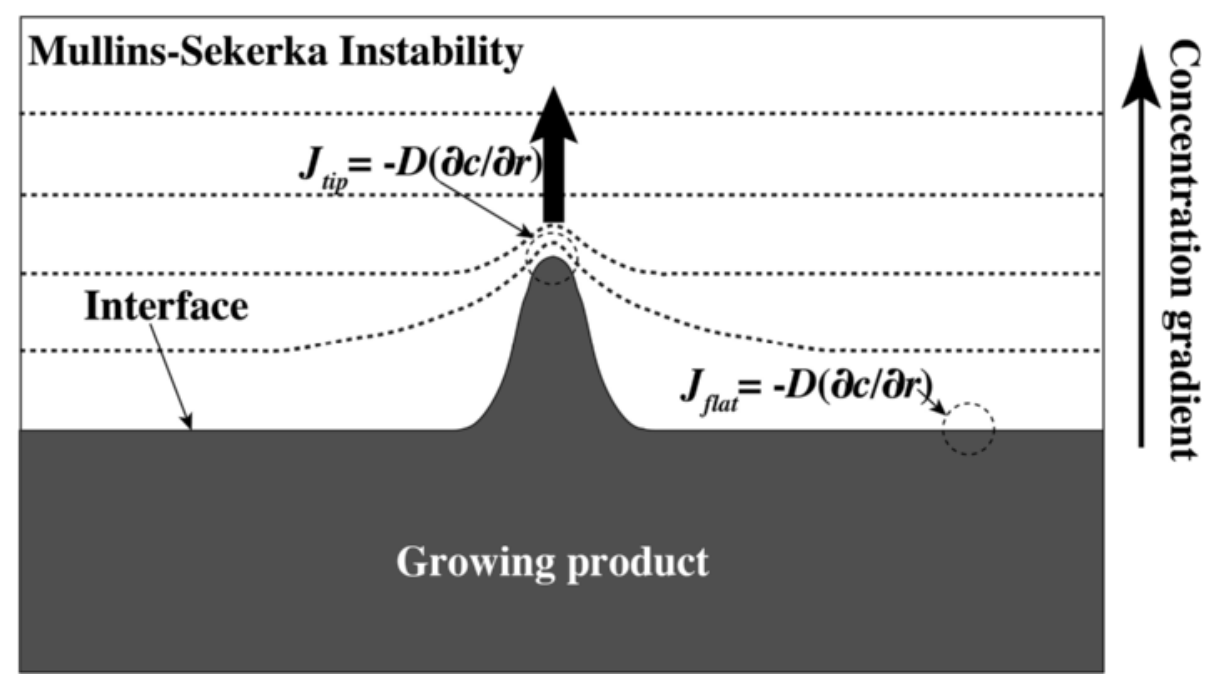

Fig. 2 Schematic diagram of diffusional instability

component (RLC) (Kelly et al. 2013a) is proportional to the concentration gradient of the RLC in the diffusional medium (see Fig. 2). This implies that diffusional instability is always to be expected under diffusion-controlled growth, and that diffusional instability will lead to highly branched textures that emerge from very small perturbations. However, interfacial energy may offset this type of instability.

Assuming the growth of a spherical product (such as a garnet porphyroblast) with radius $R_{g}$ in a diffusional medium, and a mass balance at the spherical surface, where a growth rate $\mathrm{d} V / \mathrm{d} t=4 \pi R_{g}^{2}\left(\mathrm{~d} R_{g} / \mathrm{d} t\right)$ is proportional to the diffusional flux $J=-D(\partial c / \partial r)$, the diffusion-controlled growth rate becomes:

$$
\begin{gathered}
\left(C-c_{R}\right) \frac{\mathrm{d} V}{\mathrm{~d} t}=4 \pi R_{g}^{2} D\left(\frac{\partial c}{\partial r}\right)_{r=R_{g}}, \\
\frac{\mathrm{d} R_{g}}{\mathrm{~d} t}=\frac{D}{\left(C-c_{R}\right)}\left(\frac{\partial c}{\partial r}\right)_{r=R_{g}},
\end{gathered}
$$

where $D$ is the diffusion coefficient of the RLC in the medium, $C$ is the concentration of the RLC in the product, and $r, c$, and $c_{R}$ are the distance from the center of the product, the concentration of the RLC in the diffusional medium, and the equilibrium concentration of the RLC at the interface of the product with radius $R_{g}$, respectively. Assuming the Gibbs-Thomson effect, the concentration $c_{R}$ is defined as follows:

$$
c_{R}=c_{e q}\left(1+\frac{2 \Gamma_{D}}{R_{g}}\right),
$$

where $\Gamma_{D}=\gamma \Omega / R T$ is the capillary length, and $\gamma$ and $\Omega$ are the interfacial energy and the molar volume of the product, respectively. The $R$ is the gas constant and $T$ is the temperature. The $c_{e q}$ is the equilibrium concentration of the RLC in the medium at the interface of a product with a flat surface. The $c_{R}$ is higher than $c_{e q}$ due to the GibbsThomson effect. When concentration $c$ only depends on the radial component, the diffusion equation in polar coordinates becomes $\partial c / \partial t=D\left(\partial^{2} c / \partial r^{2}+2 / r(\partial c / \partial r)\right)$. Assuming steady-state conditions (i.e., $\partial c / \partial t=0$ ), the solution of $c=c_{m}-\left(c_{m}-c_{R}\right)\left(R_{g} / r\right)$ is obtained, where $c_{m}$ is the concentration of the RLC at a long distance from the product interface. The solution satisfies $c_{r=\infty}=c_{m}$ and $c_{r=R g}=c_{R}$. Using Eqs. 1 and 2, and assuming steady-state diffusion around the spherical product of radius $R_{g}$, the growth rate $\mathrm{d} R_{g} / \mathrm{d} t$ becomes (e.g., Lifshitz and Slyozov 1961):

$$
\frac{\mathrm{d} R_{g}}{\mathrm{~d} t}=\frac{D c_{e q}}{\left(C-c_{R}\right) R_{g}}\left(\Delta \zeta-\frac{2 \Gamma_{D}}{R_{g}}\right),
$$

where $\Delta \zeta$ is the supersaturation. The $\Delta \zeta$ is defined as follows:

$$
\Delta \zeta=\frac{c_{m-} c_{e q}}{c_{e q}}
$$

Mullins and Sekerka (1963) presented a mathematical analysis of diffusional instability, and they introduced a small perturbation $\delta$ on a spherical product with radius $R_{g}$. The distorted interface of the sphere then becomes:

$$
r=R_{g}+\delta Y_{l m}(\theta, \phi),
$$

where $r$ is the distance from the center of the product to the interface, and $Y_{l m}(\theta, \phi)$ is a spherical harmonic function. The $l$ (degree) and $m$ (order) of the spherical harmonic function are integers, where $l>0$ and $-l \leq m \leq l$. The wavelength of the perturbation decreases with increasing $l$. For example, the wavelength of the small perturbation of $Y_{30}(\theta, \phi)$ is three (Fig. 3). The following 


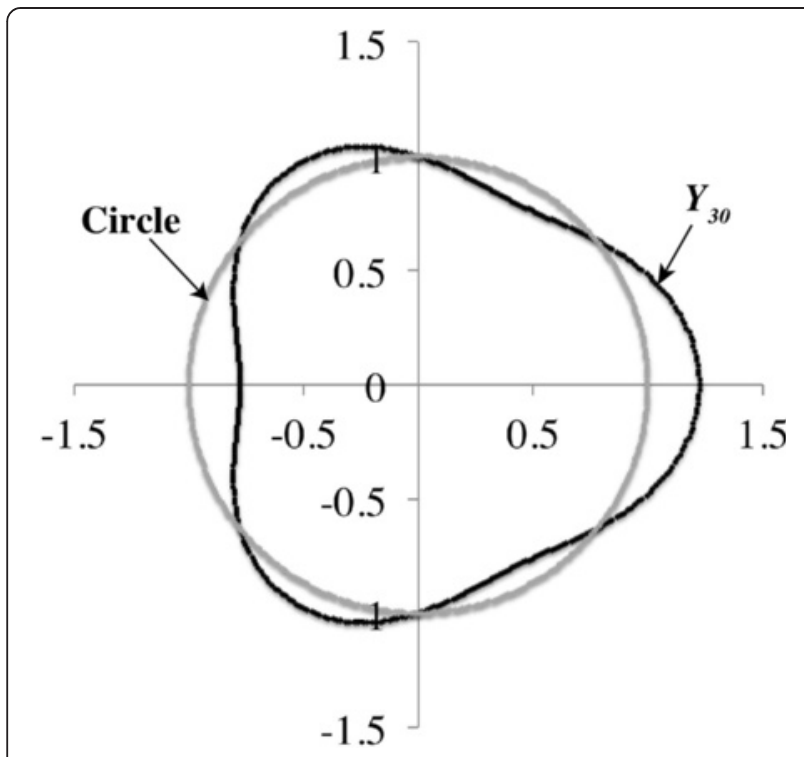

Fig. 3 A sphere perturbed by the harmonic $Y_{30}$

equation describes the relationship between degree $l$ and wavelength $\lambda_{l}$ (Mullins and Sekerka 1963):

$$
\lambda_{l} \simeq \frac{2 \pi R_{g}}{l} .
$$

A growth rate $\mathrm{d} \delta_{l} / \mathrm{d} t$ for a small perturbation $\delta_{l}$ for the degree $l$ is obtained by assuming steady-state diffusion around the growing product with radius $R_{g}$, as follows (Mullins and Sekerka 1963):

$$
\frac{\mathrm{d} \delta_{l}}{\mathrm{~d} t}=\frac{D(l-1) c_{e q}}{\left(C-c_{R}\right) R_{g}^{2}}\left\{\Delta \zeta-\Gamma_{D} \frac{(l+1)(l+2)+2}{R_{g}}\right\} \delta_{l} .
$$

The first term in the bracket on the right-hand side of Eq. 7 represents an acceleration of the perturbation due to diffusional instability, and the second term shows a reduction in the perturbation due to interfacial energy. Together, these two terms govern the evolution of the small perturbation. Using Eq. 7, the growth rate $\mathrm{d} \delta_{l} / \mathrm{d} t$ of the small perturbation can be obtained as a function of the degree $l$. Using the relationship between $l$ and $\lambda_{l}$ (Eq. 6), Fig. 4 implies that the growth rate has a maximum value at $l_{\max }$. The $l_{\max }$ is defined as follows (Mullins and Sekerka 1963):

$$
l_{\max } \equiv\left(\frac{R_{g} \Delta \zeta}{3 \Gamma_{D}}\right)^{1 / 2} .
$$

Equations 6 and 8 show that the dominant wavelength $\lambda_{\max }\left(=2 \pi R_{g} / l_{\max }\right)$ can be directly extracted from the supersaturation $\Delta \zeta$. In reverse, this means that the observed dominant wavelength of the product interface should be linked to the supersaturation.

The relative growth rate of a small perturbation for a sphere with radius $R_{g}$ is calculated using Eqs. 3 and 7, as follows:

$$
\frac{\left[\left(\mathrm{d} \delta_{l} / \mathrm{d} t\right) / \delta_{l}\right]}{\left[\left(\mathrm{d} R_{g} / \mathrm{d} t\right) / R_{g}\right]}=\frac{(l-1)\left(1-R_{l} / R_{g}\right)}{1-R_{c} / R_{g}},
$$

where $R_{l}$ is the critical radius of the diffusional perturbation of the degree $l$, and $R_{c}$ is the critical radius for Ostwald ripening. Under the condition of $R_{g}>R_{c}$, the perturbation of the degree $l$ will grow when $R_{g}>R_{l}$. In contrast, the perturbation of the degree $l$ will disappear when $R_{g}<R_{l}$. Because Eq. 9 becomes zero at $l=1$, the condition $R_{g}>R_{l=2}$ will lead to unstable growth, causing an irregular shape to form instead of a sphere. On the

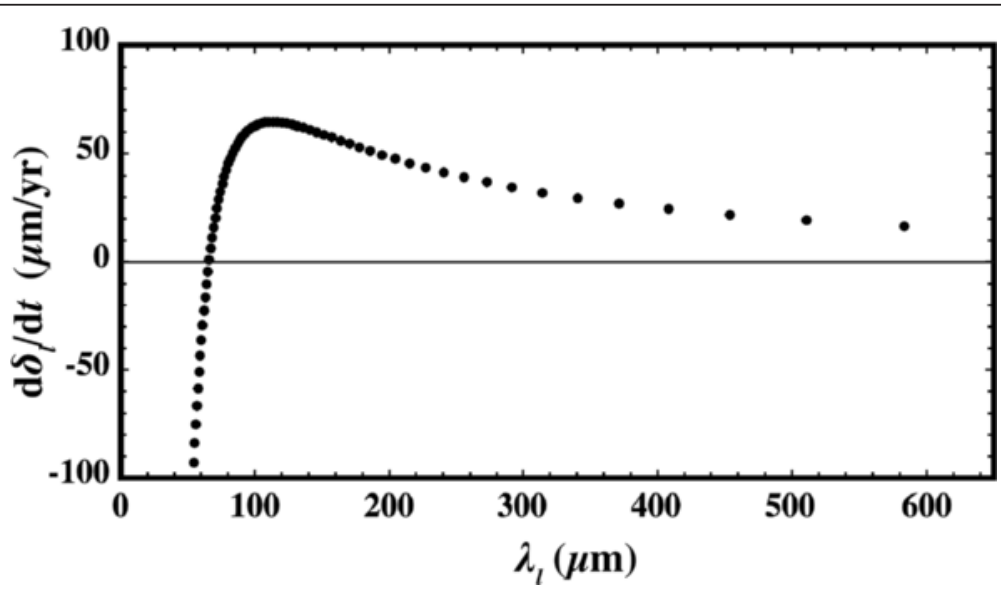

Fig. 4 Relationship between the growth rates of a perturbation on a spherical surface $(d \delta / / d t)$ and wavelength $\lambda_{\text {. }}$. The growth rate reaches a maximum value with increasing wavelength. The growth rate and wavelength are calculated using Eqs. 6 and 7 assuming an interfacial energy $\gamma=1.0 \mathrm{~J} / \mathrm{m}^{2}, C-c_{R}=1 / \Omega$, molar volume $\Omega=1.2 \times 10^{-4} \mathrm{~m}^{3} /$ mole, a capillary length $\Gamma_{D}=0.016 \mu \mathrm{m}$, a diffusion coefficient $D=10^{-19} \mathrm{~m}^{2} / \mathrm{s}$, an equilibrium concentration of the RLC $c_{e q}=10^{-4} \mathrm{~mole} / \mathrm{m}^{3}$, and a radius of the growing product $R_{g}=650 \mu \mathrm{m}$ 
other hand, when $R_{g}<R_{l=2}$, a compact spherical morphology becomes stable. Assuming a growth rate $\mathrm{d} \delta_{l} / \mathrm{d} t=0$ and $R_{g}=R_{l}$ in Eq. $7, R_{l}$ becomes:

$$
\left.R_{l}=\{(l+1)(l+2)+2)\right\} \frac{\Gamma_{D}}{\Delta \zeta} .
$$

Similarly, $R_{c}$ is given by Eq. 3 , as follows:

$$
R_{c}=\frac{2 \Gamma_{D}}{\Delta \zeta}
$$

Combining Eqs. 10 and 11, $R_{l}$ can be written as follows:

$$
R_{l}=\frac{1}{2}\{(l+1)(l+2)+2\} R_{c} .
$$

Although $R_{c}$ has a very small value, Eq. 12 implies that $R_{l}$ becomes very large for a large $l$.

\section{Measurement of the garnet morphology}

Equations 6 and 8 imply that the supersaturation $\Delta \zeta$ for diffusion-controlled growth can be directly obtained from the dominant wavelength $\lambda_{\max }$ of the interface of the growing product. Measurements of the dominant wavelength of garnet produced by diffusion-controlled growth were performed by measuring the radius of local curvature of the garnet interface (method 1), and by measuring the power spectra of the garnet interface (method 2).

In method 1 , the local curvature $k$ is characterized by the number of particles $n_{l}$ belonging to a circle with radius $r_{s}$ (Koshizuka 2005). Here, the local curvature $k=1 / r_{r}$ is calculated by counting the pixels included in a circle with radius $r_{s}$ (Fig. 5), as follows:

$$
2 \theta=\frac{n_{i}}{n_{0}} \pi
$$

$$
k=\frac{1}{r_{r}}=\frac{2 \cos \theta}{r_{s}},
$$

where $n_{i}$ is the number of pixels within circle $i$ with radius $r_{s}$. The $n_{0}$ represents $n_{\mathrm{i}}$ for a flat surface. The $r_{s}$ ranges from 3.1 to 21.1 pixel units and is adjusted to obtain the largest value of local curvature at a given position on the garnet interface. The calculated local curvatures are calibrated, as a local curvature of a circle with radius $r$ becomes $1 / r$. The calibration length ranges from $r=2$ to 120 pixel units. The calibrating local curvatures for circles with radii from $r=2$ to 120 pixel units are basically identical to the inverse of the radii of the target circles $(=1 / r)$ (Fig. 6). The dominant wavelength of the garnet interface is clearly larger than twice the length of the radius of the local curvature because the wavelength of a tip is always larger than twice the length of the radius of the enveloping circle at the tip. Hence, the lower limit for the dominant wavelength is twice the length of the radius of the local curvature.

Method 2 uses interface positions measured from the garnet barycenter to estimate the power spectra of the interface morphology. Before the measurement of interface positions, inclusions in the garnet are filled. The measured interface positions are represented by the angle $\theta$ and the distance $r$ from the barycenter (Fig. 7). A $\theta$ value of $0^{\circ}$ is defined as downward in the vertical direction from the barycenter, and the value of $\theta$ increases counterclockwise. The number of sampling points is 1024 or 2048 between $\theta=0^{\circ}$ and $360^{\circ}$ around the barycenter. The power spectra $f(\theta)$ was estimated using the fast Fourier transform (FFT) of the distance $r$ as a function of $\theta$. The dominant spectra obtained in degrees are converted to lengths by the mean radius from the barycenter of the garnet. The FFT cannot be applied to overhanging parts of the interface; therefore, only

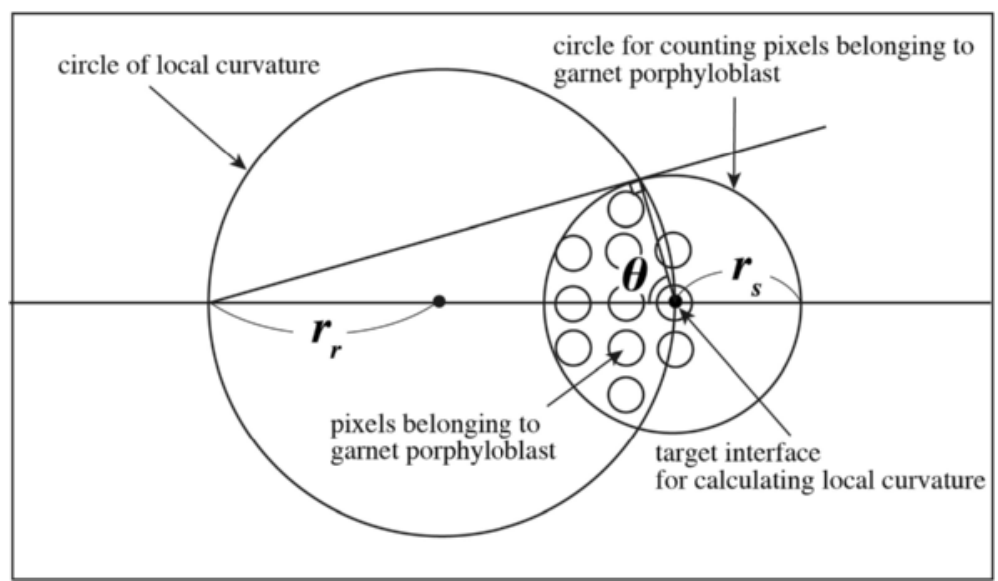

Fig. 5 Geometrical relationships between the radius of curvature and the circle radius where pixels are counted. The $r_{r}$ is the radius of curvature, and $r_{s}$ is the radius of the circle in which pixels are counted. Please see text and Eqs.13 and 14 for a detailed explanation 


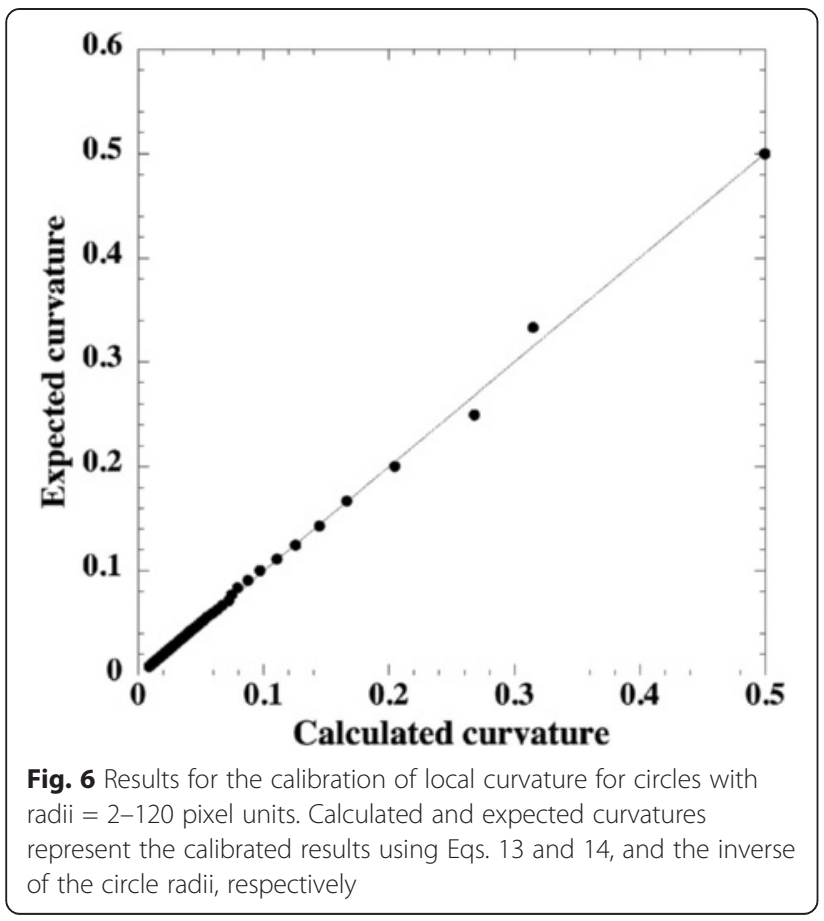

non-overhanging parts were used. This treatment leads to a lack of information on the power spectra in overhanging parts, which have many undulations (Fig. 7). Therefore, the estimates of the power spectra for shorter wavelengths are underestimated in this paper. Here, I used the dominant wavelength obtained from method 2 as the upper limit. Hence, the true value of the dominant wavelength should lie between the values obtained from methods 1 and 2.

\section{Tsukuba metamorphic rock sample}

The sample analyzed for this study was collected from the high-grade part of the Late Cretaceous low pressure-high temperature $(L P-H T)$ Tsukuba metamorphic rocks that form an eastern extension of the Ryoke metamorphic complex. The locality of the sample (number Ma2-48a) was described by Miyazaki (1999). The protoliths of the Tsukuba metamorphic rocks were mudstones and sandstones of an accretionary complex of Late Jurassic to earliest Cretaceous age (Miyazaki et al. 1996). The Tsukuba metamorphic rocks were intruded by Late Cretaceous to earliest Paleogene granitic plutons. The metamorphic grade increases from southeast to northwest.

Based on the mineral assemblages, the pelitic metamorphic rocks can be assigned to the biotite and sillimanite zones. The mineral assemblage of the biotite zone rocks is biotite + muscovite + quartz + plagioclase \pm andalusite, whereas the sillimanite zone rocks contain K-feldspar + sillimanite + biotite + quartz + plagioclase \pm cordierite \pm garnet. The boundary between the biotite and sillimanite zones is defined by the dehydration reaction of muscovite and quartz, which produces K-feldspar, sillimanite, and water. The sample analyzed for this study belongs to the high-grade part of the sillimanite zone and contains K-feldspar + garnet + cordierite + biotite + plagioclase + quartz + sillimanite The average pressure-temperature $(P-T)$ conditions of samples previously studied from the locality of the present sample are $P=0.34 \pm 0.1 \mathrm{GPa}$ and $T=642 \pm 16{ }^{\circ} \mathrm{C}$ (Miyazaki 1999).

Based on digital maps showing the distribution of minerals, as compiled from X-ray intensity maps of $\mathrm{Na}, \mathrm{K}$, $\mathrm{Mn}, \mathrm{Fe}$, and $\mathrm{Al}$, the mineral mode of the sample is $57 \%$ quartz, $22 \%$ K-feldspar, $8 \%$ plagioclase, 6-7 \% biotite, 4-5 \% cordierite, 1-2 \% garnet, and $<1 \%$ sillimanite (Miyazaki 2001). K-feldspar, biotite, plagioclase, and quartz are distributed randomly as matrix minerals with diameters of $50-60 \mu \mathrm{m}$ and do not occur as porphyroblasts (Miyazaki 2001). Because of its low abundance in the sample, it is unclear if sillimanite also has a random distribution in the matrix.

Cordierites occur as porphyroblasts (diameter $\leq 1 \mathrm{~mm}$ ) and exhibit irregular shapes. The porphyroblasts have a highly branched texture that may have been formed by diffusion-limited aggregation (DLA). The diffusion of $\mathrm{Al}$

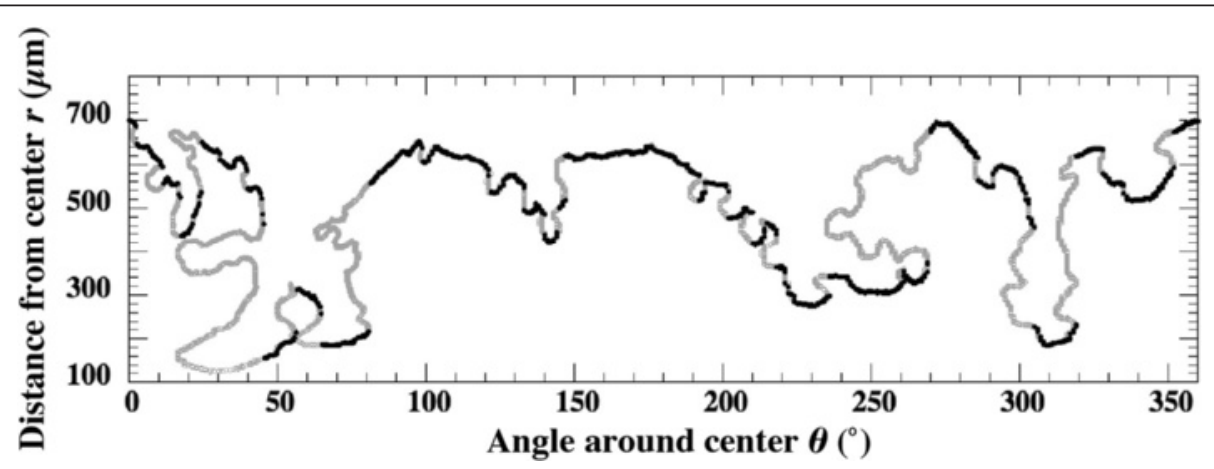

Fig. 7 Locations of the interfaces of a garnet porphyroblast (shown in Fig. 9). The locations are plotted by distance from the barycenter, and the angle around the barycenter. Black dots are used for fast Fourier transform (FFT) calculations to obtain power spectra 
may be rate-limiting for DLA-like cordierite porphyroblast growth (Miyazaki 2001). Comparisons of the morphologies and fractal dimensions of the cordierites with those of DLA indicate that formation of the cordierite porphyroblasts can be modeled as a DLA process (Miyazaki 2001). A finite-sized growth fluctuation, induced by a random distribution of matrix minerals, is amplified by the diffusional field and results in a DLA-like pattern of porphyroblast growth. Hence, diffusion-controlled growth within a random matrix field is essential for the formation of DLAlike patterns in cordierite porphyroblasts (Miyazaki 2001).

Garnets occur as porphyroblasts (diameters $\leq 1 \mathrm{~mm}$ ) and have irregular shapes (Figs. 8 and 9). Biotite is depleted around garnet porphyroblasts (Fig. 8). Quartz, cordierite, K-feldspar, and plagioclase are present in the depletion zone but biotite is rare or has smaller crystal sizes compared with biotite outside the depletion zone. Cordierite in the depletion zone is much smaller in size than the porphyroblastic cordierite (Fig. 9b). The number and size of K-feldspar grains in the depletion zone are also small compared with those outside the depletion zone (Fig. 9a). Sillimanite does not occur in the depletion zone.

The chemical compositions of the constituent minerals were given by Miyazaki (1999). The garnet contains about 7 wt $\% \mathrm{MnO}$ (73\% almandine, $16 \%$ spessartine, $9 \%$ pyrope, and $2 \%$ grossular). Compositional zoning of $\mathrm{MnO}$, $\mathrm{FeO}, \mathrm{MgO}$, and $\mathrm{CaO}$ was not detected (Fig. 9), but slightly higher $\mathrm{MnO}$ contents occur rarely at the tips on the outer rims of garnet porphyroblasts. Biotites are made up of the components phlogopite (41\%), eastonite (26\%), Ti-biotite (17\%), and muscovite (16\%). The end-member formulae of these components are phlogopite $\left(\mathrm{KM}_{3} \mathrm{AlSi}_{3} \mathrm{O}_{10}[\mathrm{OH}]_{2}\right)$, eastonite $\left(\mathrm{KM}_{2} \mathrm{Al}_{2} \mathrm{Si}_{2} \mathrm{O}_{10}[\mathrm{OH}]_{2}\right)$, Ti-biotite $\left(\mathrm{KM}_{1.5} \mathrm{TiAl}_{2}\right.$ $\left.\mathrm{Si}_{2} \mathrm{O}_{10}[\mathrm{OH}]_{2}\right)$, and muscovite $\left(\mathrm{KAl}_{3} \mathrm{Si}_{3} \mathrm{O}_{10}[\mathrm{OH}]_{2}\right)$ (e.g., Ikeda 1990), where $M$ represents the divariant cations of $\mathrm{Mg}, \mathrm{Fe}$, and $\mathrm{Mn}$. The cordierites consist of hydrous cordierite $(50 \%)$ and Fe-cordierite (50 \%). The K-feldspar contains $20 \%$ of the albite component.

\section{Garnet-forming reaction and reaction entropy}

To estimate the degree of disequilibrium, the garnetforming reaction in the sample should be identified, which is crucial for evaluating the extent of reactant depletion in the region surrounding garnet porphyroblasts. In addition, the reaction entropy $\Delta S_{r}$ for the garnet-forming reaction is required to estimate the extent to which the Gibbs free energy $\Delta G_{r}$ was overstepped. Because $\mathrm{d} G=(\partial G / \partial P) \mathrm{d} P+(\partial G / \partial T) \mathrm{d} T+$ $(\partial G / \partial N) \mathrm{d} N$, where $P$ is pressure and $N$ is the number of molecules, the Gibbs free energy depends only on $(\partial G / \partial T)=-S$ at constant pressure and bulk composition. Therefore, the reaction entropy for the garnet-forming reaction is required to estimate the overstepping of Gibbs free energy at constant pressure and bulk composition. The $\Delta G_{r}$ is calculated as follows:

$$
\Delta G_{r}=\Delta S_{r} \Delta T
$$
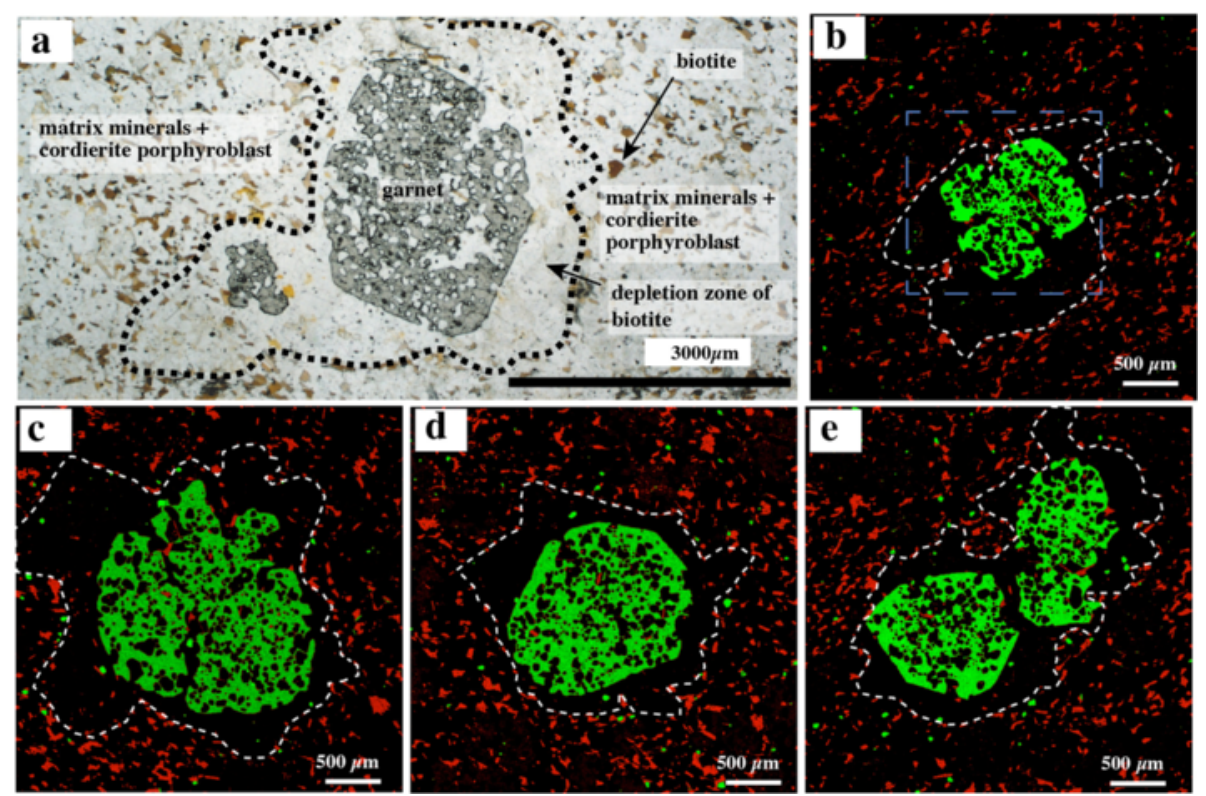

Fig. 8 Irregular and branching morphologies of garnet porphyroblasts and biotite depletion zones. a Photomicrograph. b-e Compositional maps of Fe obtained by electron probe micro-analysis (EPMA). Green and red colors represent garnet and biotite, respectively. Black broken line in (a) and white broken lines in (b)-(e) denote the area of the biotite depletion zone. Blue broken line in (b) shows area of Fig. 9a-d 

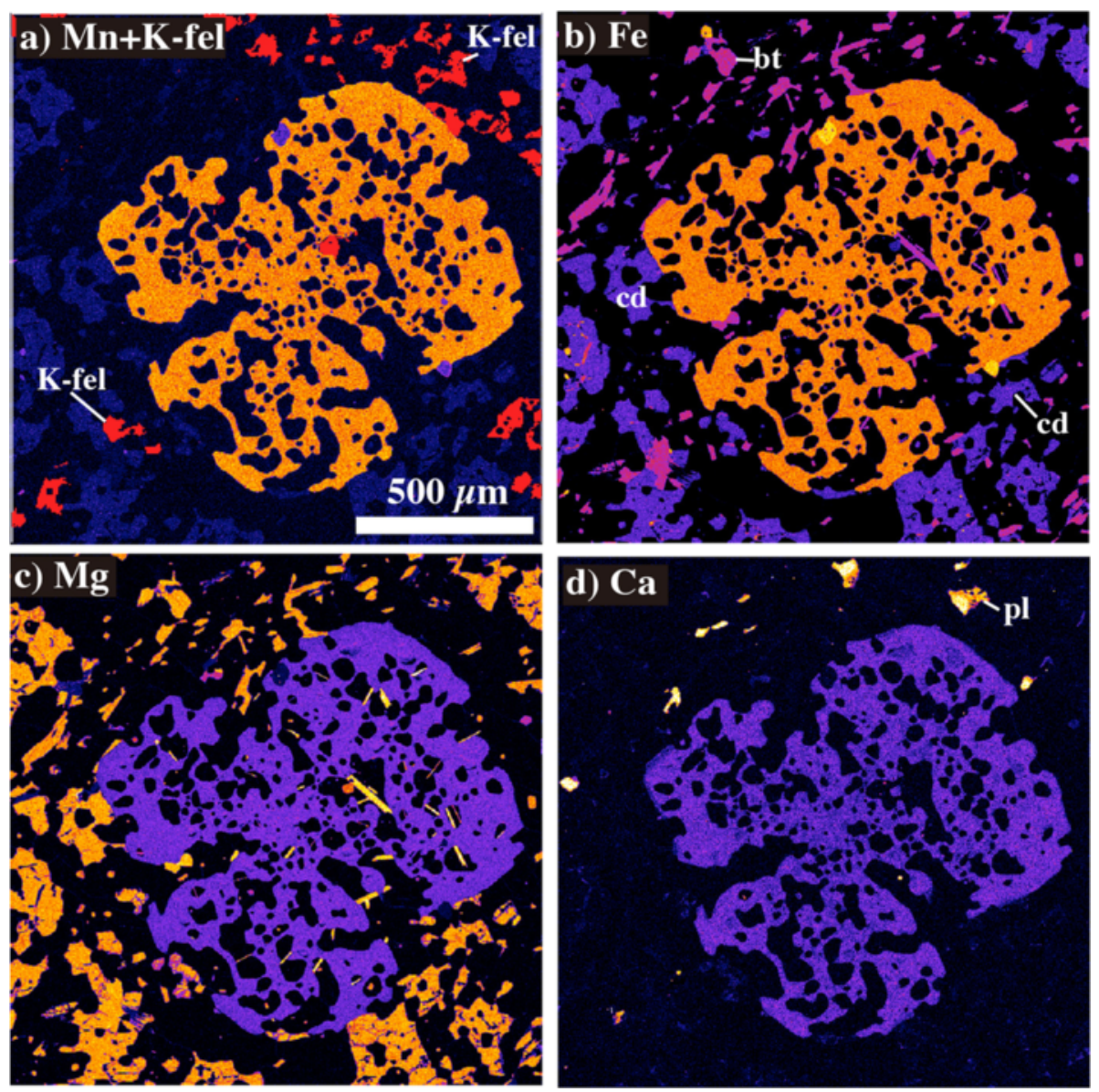

Fig. 9 Compositional maps of a garnet porphyroblast (garnet in Fig. 8b). X-ray mapping images of (a) Mn + K-fel: MnKa and distribution of K-feldspar, (b) Fe: FeKa, (c) Mg: MgKa (c), and (d) Ca: CaKa. The intensity of each X-ray increases from cooler to warmer colors. The distribution of K-feldspar (K-fel) in (a), biotite (bt) and cordierite (cd) in (b), and plagioclase (pl) in (d) are also shown

where $\Delta T$ is the temperature overstep from the equilibrium temperature. Equation 15 shows that a smaller reaction entropy will yield a larger temperature overstep at a constant overstepping of Gibbs free energy.

For simplicity, the garnet-forming reaction for the studied sample is represented by the following univariant reaction in the $\mathrm{K}_{2} \mathrm{O}-\mathrm{MgO}-\mathrm{FeO}-\mathrm{Al}_{2} \mathrm{O}_{3}-\mathrm{SiO}_{2}-\mathrm{H}_{2} \mathrm{O}$ system:

$$
\begin{aligned}
10 \text { Sillimanite } & +4 \text { Biotite }+15.5 \text { Quartz }=\text { Garnet } \\
& +4.5 \text { Cordierite }+4 \mathrm{~K}-\text { feldspar } \\
& +1.75 \text { water }
\end{aligned}
$$

The model compositions used for the minerals are listed in Table 1. In this system, garnet, biotite, and cordierite are treated as almandine-pyrope, phlogopite-annite, and hydrous cordierite-Fe-cordierite solid solutions, respectively, with the $X_{F e}$ of these minerals adjusted to the $X_{F e}$ observed in the sample. The other minerals are treated as pure phases. The spessartine component in garnet and the albite component in feldspar make minor contributions to the reaction entropy. However, the Ti-biotite, eastonite, and muscovite components in the biotite may contribute significantly to the reaction entropy by increasing the stoichiometric coefficient of water in the garnet-forming reaction. Increasing these components increases the reaction

Table 1 Mineral compositions and entropies at $642{ }^{\circ} \mathrm{C}$ (used in this paper)

\begin{tabular}{lll}
\hline Mineral & Formula & $\mathrm{S}(\mathrm{J} / \mathrm{mole} \mathrm{K})$ \\
\hline Garnet (Grt) & $\mathrm{Fe}_{2.7} \mathrm{Mg}_{0.3} \mathrm{Al}_{2} \mathrm{Si}_{3} \mathrm{O}_{12}$ & 831 \\
Biotite (Bt) & $\mathrm{KFe}_{1.8} \mathrm{Mg}_{1.2} \mathrm{AlS}_{33} \mathrm{O}_{10}(\mathrm{OH})_{2}$ & 913 \\
Sillimanite (Sil) & $\mathrm{Al}_{2} \mathrm{SiO}_{5}$ & 279 \\
Quartz (Qtz) & $\mathrm{SiO}_{2}$ & 106 \\
K-feldspar (Kfs) & $\mathrm{KAlSi}_{3} \mathrm{O}_{8}$ & 509 \\
Cordierite (Crd) & $\mathrm{FeMgAl}_{4} \mathrm{Si}_{5} \mathrm{O}_{18} \cdot\left(\mathrm{H}_{2} \mathrm{O}\right)_{0.5}$ & 1192 \\
Water (W) & $\mathrm{H}_{2} \mathrm{O}$ & 229 \\
Reaction & $4 \mathrm{Bt}+10 \mathrm{Sil}+15.5 \mathrm{Otz}=$ & 542 \\
& $\mathrm{Grt}+4 \mathrm{Kfs}+4.5 \mathrm{Crd}+1.75 \mathrm{~W}$ & \\
\hline
\end{tabular}


entropy. To obtain the minimum reaction entropy, I used a phlogopite-annite solid solution for biotite and the maximum contribution from the hydrous cordierite component.

Using the standard-state entropy and heat capacity of the end-member minerals (Holland and Powell 2011) and assuming ideal mixing for garnet, biotite, and cordierite solid solutions, the reaction entropy at $642{ }^{\circ} \mathrm{C}$ becomes $542 \mathrm{~J} / \mathrm{K}$ for the formation of 1 mole of garnet (12 oxygen atoms). The reaction entropy is also a function of temperature at constant pressure. Here, I assumed that the change in reaction entropy between 642 and $742{ }^{\circ} \mathrm{C}$ is not significantly different compared with the reaction entropy at $642{ }^{\circ} \mathrm{C}$. For example, the reaction entropy is $541 \mathrm{~J} / \mathrm{K}$ at $700{ }^{\circ} \mathrm{C}$ and $540 \mathrm{~J} / \mathrm{K}$ at $742{ }^{\circ} \mathrm{C}$.

\section{Results}

\section{Diffusional haloes around garnet porphyroblasts}

The garnet-forming reaction (Eq. 16) shows sillimanite, biotite, and quartz as the reactants and garnet, cordierite, K-feldspar, and water as the products. As shown in Fig. 8, biotite is scarce in the area surrounding the garnet porphyroblasts. Biotite is the most important reactant that supplies $\mathrm{Al}, \mathrm{Fe}$, and $\mathrm{Mg}$ to a growing garnet crystal. Therefore, the observed depletion of biotite around garnet porphyroblasts provides direct evidence for diffusion-controlled growth. The depletion zone is recognized as diffusional haloes around garnet porphyroblasts. Sillimanite is also an important reactant that supplies $\mathrm{Al}$ to garnet, but it is scarce in the matrix. Because sillimanite is typically found farther away from the garnet, the depletion zone of sillimanite around the garnet is much more difficult to identify than the biotite depletion zone.

Cordierite and K-feldspar are products of the garnetforming reaction. The cordierite crystals in the depleted zone are much smaller than the porphyroblastic cordierite. The number and size of K-feldspar grains in the depletion zone are also smaller than outside the depletion zone. These observations indicate that growth of cordierite and K-feldspar within the depleted zone was suppressed in comparison with growth of cordierite porphyroblasts and K-feldspar matrix minerals outside the depletion zone.

\section{Dominant wavelength and supersaturation}

Histograms of the radii of the local interface curvature of seven garnets within the sample show a peak around 30-70 $\mu \mathrm{m}$ (Fig. 10). This peak corresponds to the highest frequency of radii measured from local curvatures of undulations in the irregular garnets. As mentioned above, the wavelengths of these undulations are larger than twice the radius of the local curvatures. Using the mid-range values of the histogram peaks for the seven garnet crystals, the calculated average radius of the local curvatures is $43 \pm 4.5 \mu \mathrm{m}$ (Table 2). Therefore, the dominant wavelength obtained from method 1 should be greater than $86 \mu \mathrm{m}$.

The power spectra of the interface of irregular garnets show a broad maximum around 150-700 $\mu \mathrm{m}$ (Fig. 11). Using the mid-range values of these maxima, the calculated average value is $489 \pm 88 \mu \mathrm{m}$ (Table 2). Therefore, the dominant wavelength obtained from method 2 should be smaller than $489 \mu \mathrm{m}$.

Given a dominant wavelength between 86 and $489 \mu \mathrm{m}$, interfacial energy $\gamma=1.0 \mathrm{~J} / \mathrm{m}^{2}$ (Miyazaki 1991), molar volume $\Omega=1.2 \times 10^{-4} \mathrm{~m}^{3} /$ mole (Miyazaki 1991), $T=642{ }^{\circ} \mathrm{C}$, and a capillary length $\Gamma_{D}=\gamma \Omega / R T=1.58 \times 10^{-5} \mathrm{~mm}$ for garnet, Eqs. 6 and 8 yield a supersaturation $\Delta \zeta$ of $0.05 \times$ $10^{-1}-0.16$ for garnet using the observed average garnet radius of $644 \mu \mathrm{m}$. By decreasing the supersaturation $\Delta \zeta$, the dominant wavelength becomes larger (Fig. 12). Taking the average value of the lower and upper boundaries for the dominant wavelength $(288 \mu \mathrm{m}$; see Table 2$)$, a $\Delta \zeta$ value of $0.15 \times 10^{-1}$ is calculated. The average value of the dominant wavelength is consistent with the crude spacing of undulations along the irregular interface of garnet porphyroblasts (Figs. 8 and 9).

\section{Gibbs free energy and temperature oversteps}

The calculated supersaturation can be used to determine the magnitude of Gibbs free energy and temperature oversteps. The sample retains the reactant mineral assemblage of sillimanite + biotite + quartz in areas distant from the garnet porphyroblasts. Conversely, the product mineral assemblage of K-feldspar + cordierite occurs proximal to the garnet porphyroblast. Assuming that reactants far from the garnet porphyroblast are locally in equilibrium with the diffusive medium, the chemical potential difference $\Delta \mu_{\text {dissolution }}$ for dissolution of a reactant is

$$
\Delta \mu_{\text {dissolution }}=\mu_{\text {reactant }}-\mu_{\mathrm{IGM}}=0 .
$$

Here, $\mu_{\text {reactant }}$ is the chemical potential of the reactant and $\mu_{\mathrm{IGM}}$ is the chemical potential of the chemical species dissolved in the intergranular medium. The $\mu_{\mathrm{IGM}}$ is expressed as follows:

$$
\begin{aligned}
& \mu_{\mathrm{IGM}}=\sum_{i} m_{i} \mu_{i}+m_{\mathrm{RLC}} \mu_{\mathrm{RLC}}, \\
& \mu_{\mathrm{RLC}}=\mu_{\mathrm{RLC}}^{0}+R T \ln X_{\mathrm{RLC}, m},
\end{aligned}
$$

where $m_{i}$ is the number of moles of chemical species $i$ exclusive of the RLC that enter or leave the intergranular fluid in the reactant-dissolution and product-precipitation reactions, $\mu_{i}$ is the chemical potential of chemical species $i$ exclusive of the RLC, $m_{\mathrm{RLC}}$ is the number of moles the RLC, and $\mu_{\text {RLC }}$ is the chemical potential of the RLC. The summation in Eq. 18 excludes the chemical potential 

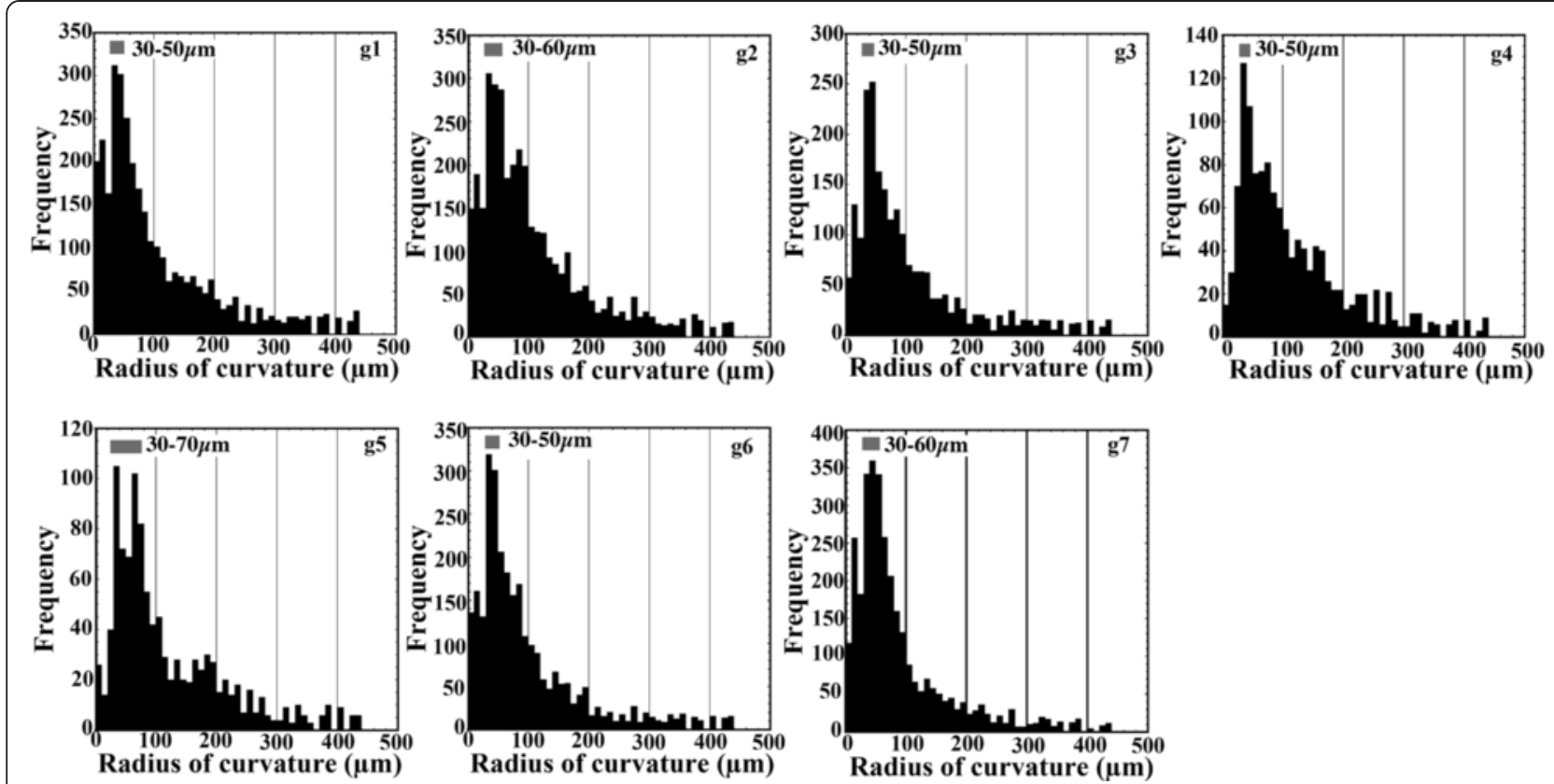

Fig. 10 Histograms of the radius of curvature for irregularly shaped interfaces of garnet porphyroblasts. The gray-colored horizontal bar represents the range of the radius peaks for each sample

of the RLC. In Eq. 19, the $\mu_{\mathrm{RLC}}^{0}$ is the chemical potential of the pure (unmixed) RLC and $X_{\mathrm{RLC}, m}$ is the mole fraction of the RLC in the intergranular medium at a site distant from the garnet porphyroblast. Equation 19 assumes ideal mixing of the RLC in the intergranular medium. In the diffusion-controlled regime, $X_{\mathrm{RLC}, m}$ varies between areas proximal to and distant from the garnet porphyroblast. Hence, Eq. 17 becomes

$$
\Delta \mu_{\text {dissolution }}=\mu_{\text {reactant }}-\mu_{\mathrm{IGM} 0}-m_{\mathrm{RLC}} R T \ln X_{\mathrm{RLC}, m}=0 .
$$

Assuming the products around the garnet porphyroblast are locally in equilibrium with the diffusive medium, the chemical potential difference $\Delta \mu_{\text {precipitation for a product }}$ surrounding the garnet porphyroblast is

$$
\Delta \mu_{\text {precipitation }}=\mu_{\text {product }}-\mu_{\mathrm{IGMO}}-m_{\mathrm{RLC}} R T \ln X_{\mathrm{RLC}, g r t}=0
$$

where $\mu_{\text {product }}$ is the chemical potential of the product and $X_{\mathrm{RLC}, g r t}$ is the mole fraction of the RLC around the garnet porphyroblast. Because garnet growth is controlled by the slowest diffusion of the RLC, the chemical potential differences of the intergranular medium between the areas proximal to and distant from the garnet

\begin{tabular}{|c|c|c|c|c|c|c|c|}
\hline Garnet & $R_{g}:$ radius $(\mu \mathrm{m})$ & $\begin{array}{l}\text { a: mid-range } \\
\text { of radius of } \\
\text { curvature }(\mu \mathrm{m})\end{array}$ & $\begin{array}{l}b \text { : mid-range } \\
\text { of dominant } \\
\text { wavelength }(\mu \mathrm{m})\end{array}$ & $\begin{array}{l}\text { c: average of the } \\
\text { dominant } \\
\text { wavelengths by } \\
2 \times \text { a and b }(\mu \mathrm{m})\end{array}$ & $\begin{array}{l}\Delta \zeta^{\text {a }} \text { lower bound } \\
\text { calculated with } \\
\text { value of } b\end{array}$ & $\begin{array}{l}\Delta \zeta^{* a} \text { mid-range } \\
\text { value calculated } \\
\text { with value of } c\end{array}$ & $\begin{array}{l}\Delta \zeta^{* a} \text { upper bound } \\
\text { calculated with value } \\
\text { of } 2 \times a\end{array}$ \\
\hline g1 & 780 & 40 & 500 & 270 & $0.06 \times 10^{-1}$ & 0.02 & 0.23 \\
\hline 92 & 904 & 45 & 550 & 298 & $0.06 \times 10^{-1}$ & 0.02 & 0.21 \\
\hline g3 & 536 & 40 & 425 & 233 & $0.06 \times 10^{-1}$ & 0.02 & 0.16 \\
\hline g4 & 541 & 40 & 550 & 295 & $0.03 \times 10^{-1}$ & 0.01 & 0.16 \\
\hline g5 & 479 & 50 & 300 & 175 & 0.01 & 0.03 & 0.09 \\
\hline g6 & 702 & 40 & 550 & 295 & $0.04 \times 10^{-1}$ & 0.02 & 0.20 \\
\hline g7 & 568 & 45 & 550 & 298 & $0.04 \times 10^{-1}$ & 0.01 & 0.13 \\
\hline Average & 644 & 43 & 489 & $288^{b}$ & $0.05 \times 10^{-1 c}$ & $0.15 \times 10^{-1 c}$ & $0.16^{c}$ \\
\hline
\end{tabular}

Table 2 Radius of curvature and dominant wavelength of garnet porphyroblast interfaces, and the estimated supersaturation ( $\Delta \zeta)$

${ }^{\mathrm{a}}$ Calculated using Eq. 8, with $\Gamma_{D}=1.58 \times 10^{-5} \mathrm{~mm}$

${ }^{\mathrm{b}}$ Calculated with average values of $2 \times \mathrm{a}$ and $\mathrm{b}$

${ }^{c}$ Calculated with average values of radius $R_{\mathrm{g}}, 2 \times \mathrm{a}, \mathrm{b}$, and c 

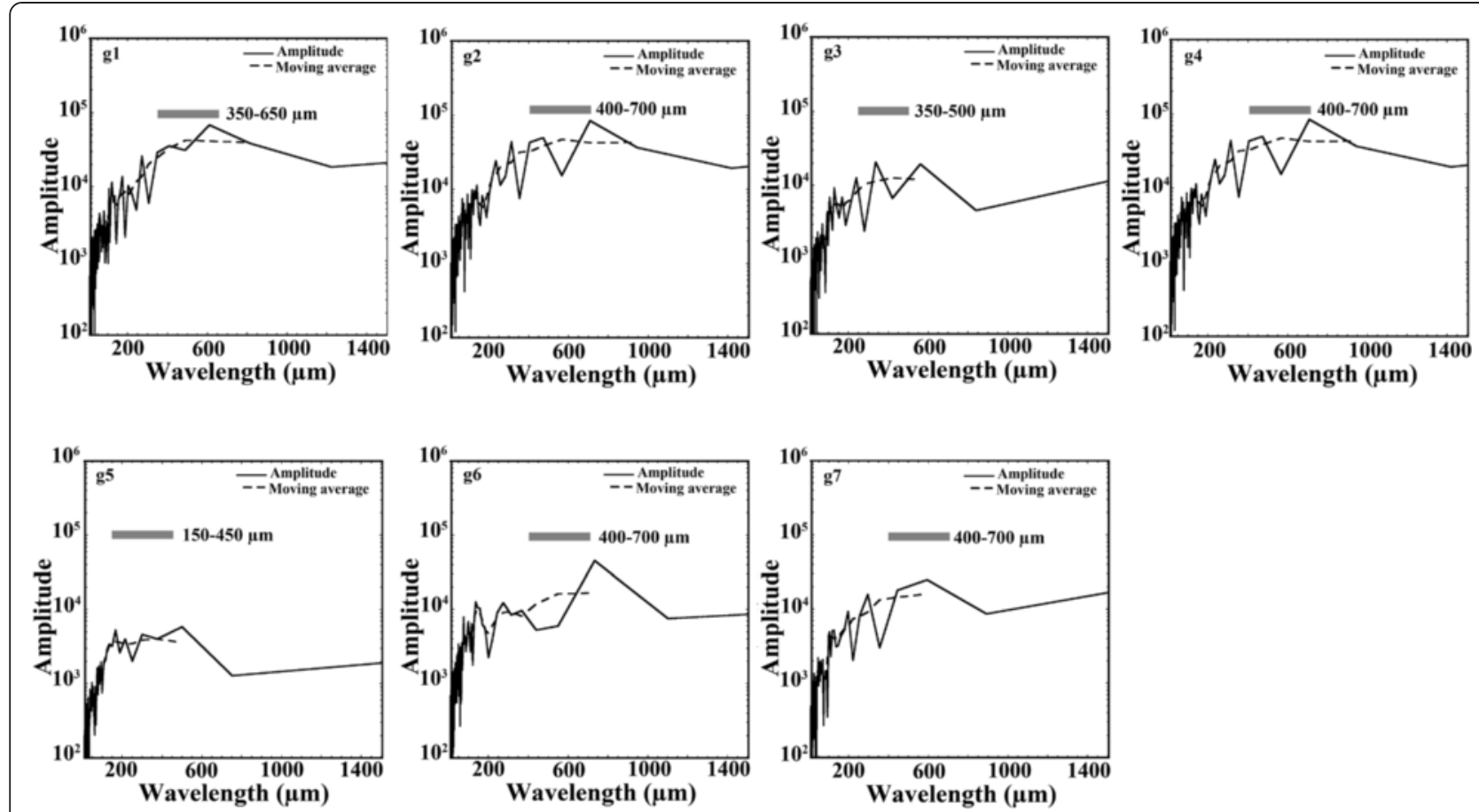

Fig. 11 Power spectra for the wavelengths of irregularly shaped interfaces of garnet porphyroblasts. Broken lines show the moving average of the power spectra. The gray-colored horizontal bar represents the range of the dominant wavelength for each sample

porphyroblast depend on the chemical potential of the RLC in the medium. This constancy indicates that $\mu_{\mathrm{IGM}}$ in Eq. 20 has the same value as in Eq. 21. Using Eqs. 20 and 21, the mole fractions of the most sluggish component of the RLC become

$$
X_{\mathrm{RLC}, m}=\operatorname{Exp}\left(\frac{\mu_{\text {reactant }}-\mu_{\mathrm{IGM} 0}}{m_{\mathrm{RLC}} R T}\right)
$$

$$
X_{\mathrm{RLC}, \mathrm{grt}}=\operatorname{Exp}\left(\frac{\mu_{\mathrm{product}}-\mu_{\mathrm{IGM0}}}{m_{\mathrm{RLC}} R T}\right)
$$

From Eqs. 4, 22, and 23, the supersaturation $\Delta \zeta$ becomes

$$
\Delta \zeta=\frac{c_{m}-c_{e q}}{c_{e q}}=\frac{a X_{\mathrm{RLC}, m}-a X_{\mathrm{RLC}, g r t}}{a X_{\mathrm{RLC}, \mathrm{grt}}}
$$

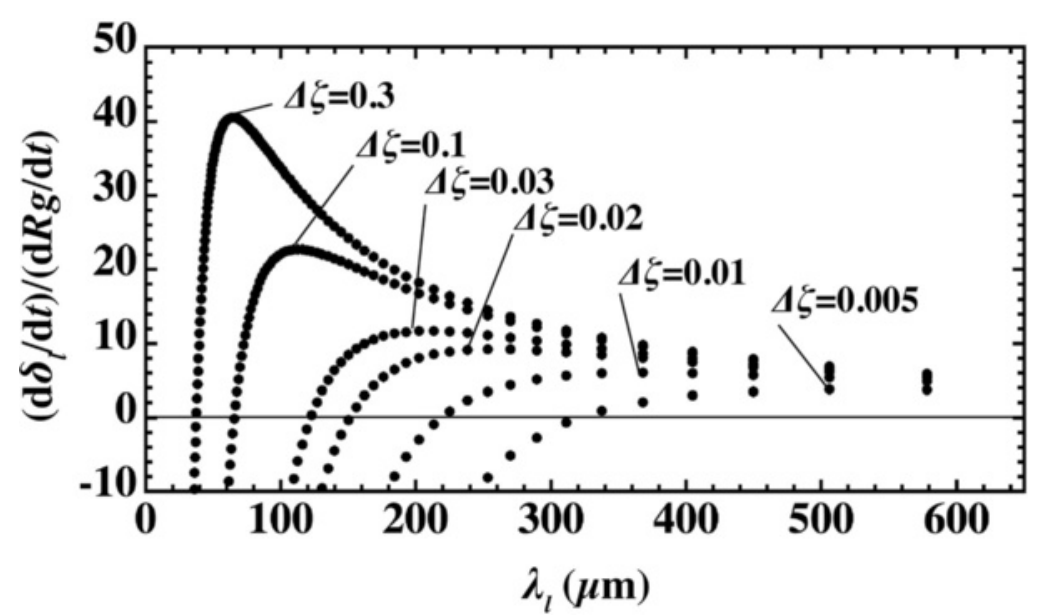

Fig. 12 Relative growth rate of a sphere perturbation relative to the growth rate of a sphere. The relative growth rate $\left(\left(\mathrm{d} \delta_{/} / \mathrm{d} t\right) /\left(\mathrm{d} R_{g} / \mathrm{d} t\right)\right)$ is a function of wavelength $\lambda_{\text {}}$. The relative growth rate is calculated using Eqs. $6,9,10$, and 11, with $\Gamma_{D}=1.58 \times 10^{-5} \mathrm{~mm}, R_{g}=644 \mu \mathrm{m}$, and $\Delta \zeta=$ $0.05 \times 10^{-1}-0.3$ 


$$
\Delta \zeta=\operatorname{Exp}\left(\frac{\Delta G_{r}}{m_{\mathrm{RLC}} R T}\right)-1
$$

where $a$ is a constant for converting from a mole fraction to concentration, and $\Delta G_{r}=\mu_{\text {reactant }}-\mu_{\text {product }}$ is the Gibbs free energy for the garnet-forming reaction (Eq. 16). The $\Delta G_{r}$ in this study is equivalent to reaction affinity $A$ (e.g., Pattison et al. 2011) and $\Delta G_{r}$ is zero at the equilibrium temperature. I assumed that the RLC is $\mathrm{Al}$, corresponding to $m_{\mathrm{RLC}}=24$, and that the equilibrium temperature is $T=642{ }^{\circ} \mathrm{C}$. Using Eq. 25, the supersaturation $\Delta \zeta$ of $0.05 \times 10^{-1}-0.16$ yields a $\Delta G_{r}$ of $0.9-$ $27 \mathrm{~kJ}$ per mole of garnet (12 oxygen atoms). The average $\Delta \zeta$ of $0.15 \times 10^{-1}$ yields a $\Delta G_{r}$ of $2.7 \mathrm{~kJ}$ per mole of garnet.

Using Eq. 15, $\Delta G_{n}$ and the reaction entropy $\Delta S_{r}$ of $542 \mathrm{~J} / \mathrm{K}$ per mole of garnet for the garnet reaction, a temperature overstep $\Delta T$ of $1.7-50{ }^{\circ} \mathrm{C}$ is calculated using the lower and upper boundaries of the dominant wavelength. When the average dominant wavelength is used, a $\Delta T$ of $5{ }^{\circ} \mathrm{C}$ is calculated.

\section{Discussion}

Estimates of the degree of disequilibrium for the garnetforming reaction have been reported in previous studies. Pattison and Tinkham (2009) evaluated the temperature and Gibbs free energy oversteps for a garnet-forming reaction in the Nelson aureole (British Columbia) using discrepancies between phase-equilibrium modeling and field observations of the location of the garnet isograd. This approach yielded $\Delta T=30{ }^{\circ} \mathrm{C}$ and $\Delta G_{r}=4.8 \mathrm{~kJ}$ per mole of garnet. The degree of disequilibrium for the Nelson aureole is similar to that calculated for the sample in this study. However, the garnet porphyroblasts in the Nelson aureole are euhedral rather than irregular and branching in the case of the garnets from the Tsukuba metamorphic rocks. Kinetic modeling based on interface-controlled nucleation and growth was used to explain the formation of the garnet in the Nelson aureole (Gaidies et al. 2011). On the other hand, Kelly et al. (2013b) used numerical modeling of diffusioncontrolled nucleation and growth to reproduce the crystal sizes and spatial distributions of minerals in 13 porphyroblastic rocks. They calculated $\Delta T=5-67{ }^{\circ} \mathrm{C}$ and $\Delta G_{r}=0.7-5.8 \mathrm{~kJ}$ per mole of garnet. Spear et al. (2014) also evaluated the degree of disequilibrium for the garnet-forming reaction. Using a combination of quartz in garnet barometry (QuiG) and thermodynamic modeling for garnet zone metamorphic rocks in eastern Vermont, they calculated a $\Delta T$ of $10^{\circ} \mathrm{C}$, a pressure overstep of $0.6 \mathrm{kbar}$, and a $\Delta G_{r}$ of $2 \mathrm{~kJ}$ per mole of garnet. For the staurolite-kyanite zone in the same metamorphic terrain and for a blueschist sample from Sifnos, Greece, Spear et al. (2014) calculated a $\Delta T$ of $50{ }^{\circ} \mathrm{C}$, a pressure overstep of $2-5 \mathrm{kbar}$, and a $\Delta G_{r}$ of $10-18 \mathrm{~kJ}$ per mole of garnet. Although diverse methods have been used to infer the degree of disequilibrium for the garnetforming reaction, the calculated values suggest that in all cases the garnet nucleated and grew after a significant overstep from equilibrium conditions.

Wilbur and Ague (2006) used Monte Carlo simulations of crystal growth to demonstrate the formation of irregular and branching morphologies in garnet porphyroblasts. Because this simulation assumed random walk of chemical species, the morphology was produced by diffusion-controlled growth. They determined that a minimum Gibbs free energy overstep of about $2 \mathrm{~kJ}$ per mole of garnet was needed to produce a branched morphology for silicate minerals (Wilbur and Ague 2006). This value is consistent with the Gibbs free energy overstep calculated in this paper. Spear and Daniel (2001) proposed an amoeba-like growth model for garnet porphyroblasts based on observations of heterogeneous chemical zoning. This model supports the development of an irregular and branching morphology in garnet porphyroblasts. Collectively, the results obtained using these different approaches suggest that the irregular and branching morphology of garnet porphyroblasts is indicative of diffusion-controlled growth.

Ostwald ripening and grain growth are not considered in this paper because the garnets occur as porphyroblasts, meaning that the size of the garnet crystals is much larger than the surrounding matrix minerals. Because grain growth associated with Ostwald ripening takes place due to the reduction of interfacial energy when the system is close to equilibrium, this mechanism should occur at a faster rate for smaller grain sizes. Hence, grain growth due to Ostwald ripening is only important for non-porphyroblastic minerals.

Figure 13 summarizes the relationships among supersaturation, temperature oversteps, and the critical grain diameter for diffusional instability with respect to the diffusion-controlled growth of garnet porphyroblasts in the Tsukuba metamorphic rocks. It is clear that nucleation occurs after a significant overstep from equilibrium conditions for the garnet-forming reaction. Figure 13 shows two different trends in garnet size vs. degree of supersaturation, with path-A and path-B representing nearly constant supersaturation and decreasing supersaturation during garnet growth, respectively. The supersaturation should decrease with consumption of the garnet component in the system. The rate of decrease of the garnet component depends on the relative magnitudes of the garnet precipitation rate and the dissolution rate of reactants in the garnet-forming reaction. Both rates are limited by diffusion of the RLC. For simplicity, it was assumed that the garnet and reactant crystals are the same size. 


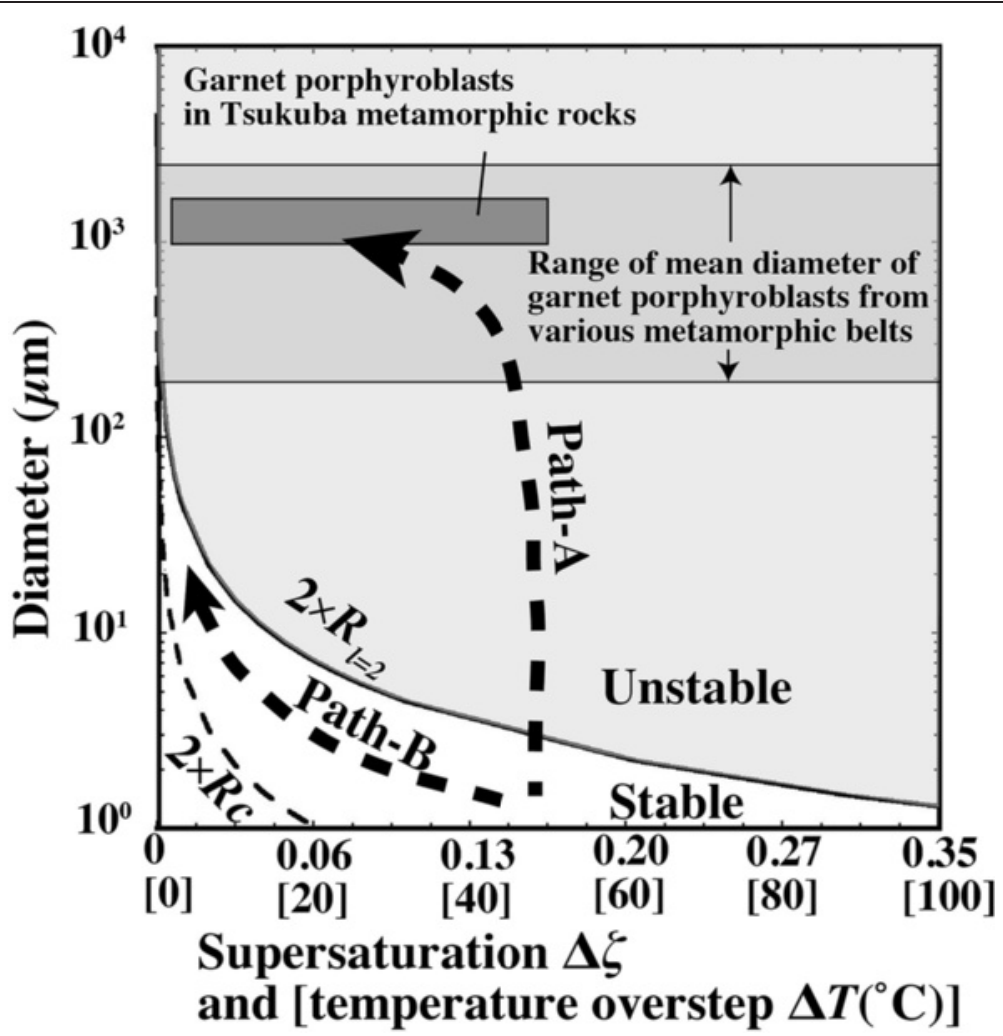

Fig. 13 Relationships among supersaturation, temperature overstep, and critical diameter $2 \times R_{l=2}$ for diffusional instability. The $2 \times R_{c}$ represents the critical diameter for Ostwald ripening. The $R_{l=2}$ and $R_{c}$ are calculated using Eqs.10 and 11, and $\Gamma_{D}=1.58 \times 10^{-5} \mathrm{~mm}$. The measured diameters of the garnet porphyroblasts, the estimated supersaturation (calculated using Eq. 8 and $R_{g}=644 \mu \mathrm{m}$ ), and the temperature overstep (calculated using Eqs. 15 and 25, $\Delta S=542 \mathrm{~J} / \mathrm{K}$ per mole of garnet, and assuming 12 oxygen atoms) for the Tsukuba metamorphic rocks are shown (dark gray box). Two representative evolution paths (path-A and path-B) are also shown. See the text for detailed explanations of these paths. The range of mean diameters of garnet porphyroblasts from various metamorphic belts is based on the data of Gaidies et al. (2011) and Kelly et al. (2013b) (gray box)

If the number of garnet crystals is much fewer than the number of reactant crystals, the evolution of garnet size and degree of supersaturation should follow path-A. For diffusion-controlled growth in this case, a small nucleation rate and large number of reactant crystals favor the growth of a small number of garnet crystals, thus producing unstable porphyroblastic garnet. Large garnet porphyroblasts with irregular and branching morphologies will form. Conversely, if the number of garnet crystals is much larger than the number of reactant crystals, the evolution of garnet size and degree of supersaturation should follow pathB. Due to a high nucleation rate and a small number of reactant crystals, many small garnets should grow rather than porphyroblasts. In addition, path-B promotes a stable garnet morphology, thus preventing the formation of branching and irregular textures.

Kelly et al. (2013b) proposed diffusion-controlled growth for the formation of garnet porphyroblasts whereas Gaidies et al. (2011) proposed interface-controlled growth. Based on the mean radii of garnet porphyroblasts measured in these studies, the mean diameters of garnet porphyroblasts range from 180 to $2400 \mu \mathrm{m}$ (Fig. 13). Most diameters fall in the range of 1000 to $2000 \mu \mathrm{m}$. Therefore, diffusion-controlled growth of garnet porphyroblasts without the development of irregular and branching morphology is difficult to achieve. This finding contradicts the hypothesis that diffusion-controlled growth of garnet porphyroblasts dominates in nature, which is consistent with the rarity of irregular and branching garnet porphyroblasts in metamorphic belts.

Over a scale of $10 \mathrm{~cm}$, temperature heterogeneities produced by the growth of a garnet porphyroblast will be quickly dissipated over a time interval significantly shorter than the long growth period of the porphyroblast. This reasoning indicates that a control on porphyroblast growth by heat flow is unlikely. Therefore, the results of this study suggest that garnet porphyroblasts lacking an irregular and branching morphology (common in many metamorphic belts) may grow at a high degree of disequilibrium under interfacial-controlled growth, provided they are set in a medium in which diffusion is rapid 
and the supply of elements from metamorphic fluids is sufficient.

\section{Conclusions}

Garnet porphyroblasts with an irregular morphology and a diffusional halo of reactants occur in the $L P-H T$ Tsukuba metamorphic rocks of central Japan. The features observed suggest diffusion-controlled growth of the porphyroblasts.

Using an analysis of diffusional instability, the degree of disequilibrium can be determined by measuring the dominant wavelength of the interface of the garnet porphyroblasts. The results show that the supersaturation is $0.05 \times 10^{-1}-0.16$. From the extent of supersaturation, the calculated overstep of Gibbs free energy from equilibrium is $0.9-27 \mathrm{~kJ}$ per mole of garnet (12 oxygen atoms), and the temperature overstep is $1.7-50{ }^{\circ} \mathrm{C}$.

A high degree of disequilibrium for a garnet-forming reaction is expected during growth of a garnet porphyroblast after nucleation. The present results suggest that garnet porphyroblasts that lack irregular and branching morphologies, a typical feature of many metamorphic belts, may grow at a high degree of disequilibrium under interfacial-controlled growth, provided they are set in a medium where diffusion and the supply of elements is sufficient, such as a sufficient volume of metamorphic fluid.

\section{Abbreviations}

FFT: fast Fourier transform; QuiG: quartz in garnet barometry; RLC: rate-limiting component.

\section{Competing interests}

The author declares that he has no competing interests.

\section{Acknowledgements}

The author would like to express his gratitude to Dr. Tetsuo Kawakami and Kazuhiko Ishii who were conveners of the Japan Geoscience Union session on "Deformed Rocks, Metamorphic Rocks and Tectonics" for encouraging me to submit this paper to PEPS. I also thank two anonymous reviewers for their constructive reviews, comments, and suggestions that helped to improve the manuscript.

Received: 18 March 2015 Accepted: 12 August 2015

Published online: 02 September 2015

\section{References}

Ague JJ, Carlson WD (2013) Metamorphism as garnet sees it: the kinetics of nucleation and growth, equilibration, and diffusional relaxation. Elements 9:439-445

Carlson WD (1989) The significance of intergranular diffusion to the mechanisms and kinetics of porphyroblast crystallization. Contrib Mineral Petrol 103:181-200

Fisher GW (1978) Rate laws in metamorphism. Geochim Cosmochim Acta 42:1035-1050

Gaidies F, Pattison DRM, de Capitani C (2011) Toward a quantitative model of metamorphic nucleation and growth. Contrib Mineral Petrol 162:974-993

Holland TJB, Powell R (2011) An improved and extended internally consistent thermodynamic dataset for phases of petrological interest, involving a new equation of state for solids. J Metamorph Geol 29:333-383
Ikeda T (1990) Ti endmember composition of biotite. Ti substitution in biotite from Ryoke metamorphic rocks in the Yanai district. J Mineral Petrol Sci 85:357-363

Kelly ED, Carlson WD, Ketchman RA (2013a) Crystallization kinetics during regional metamorphism of porphyroblastic rocks. J Metamorph Geol 31:963-979

Kelly ED, Carlson WD, Ketchman RA (2013b) Magnitudes of departures from equilibrium during regional metamorphism of porphyroblastic rocks. J Metamorph Geol 33:981-1002

Koshizuka S (2005) The MPS method. Maruzen Ltd, Tokyo

Lifshitz IM, Slyozov W (1961) The kinetics of precipitation from supersaturated solid solutions. J Phys Chem Solids 19:35-50

Miyazaki K (1991) Ostwald ripening of garnet in high $\mathrm{P} / \mathrm{T}$ metamorphic rocks. Contrib Mineral Petrol 108:118-128

Miyazaki K (1996) A numerical simulation of textural evolution due to Ostwald ripening in metamorphic rocks: a case for small amount of volume of dispersed crystals. Geochim Cosmochim Acta 60:277-290

Miyazaki K (1999) Thermobarometry of the Tsukuba Metamorphic Rocks. Bull Geol Surv Japan 50:515-525

Miyazaki K (2001) Heterogeneous growth of cordierite in low P/T Tsukuba metamorphic rocks from central Japan. J Metamorph Geol 19:155-164

Miyazaki K, Sasada M, Yoshioka T (1996) Geology of the Makabe district, with geological sheet map at 1:50,000. Geological Survey of Japan, Tsukuba

Mullins WW, Sekerka RF (1963) Morphological stability of a particle growing by diffusion or heat flow. J Applied Phys 34:323-329

Pattison DRM, Tinkham DK (2009) Interplay between equilibrium and kinetic in prograde metamorphism of pelites: an example from the Nelson aureole, British Columbia. J Metamorph Geol 27:249-279

Pattison DRM, de Capitani C, Gaides F (2011) Petrological consequences

of variations in metamorphic reaction. J Metamorph Geol 29:953-977

Spear FS, Daniel CG (2001) Diffusion control of garnet growth, Harpswell Neck, Maine, USA. J Metamorph Geol 19:179-195

Spear FS, Thomas JB, Hallet BW (2014) Overstepping the garnet isograd: a comparison of QuiG barometry and thermodynamic modeling. Contrib Mineral Petrol 168:1059

Walther JV, Wood BJ (1984) Rate and mechanism in prograde metamorphism. Contrib Mineral Petrol 88:246-259

Wilbur DE, Ague JJ (2006) Chemical disequilibrium during garnet growth: Monte Carlo simulations of natural crystal morphologies. Geology 34:689-692

\section{Submit your manuscript to a SpringerOpen ${ }^{\odot}$ journal and benefit from:}

- Convenient online submission

Rigorous peer review

- Immediate publication on acceptance

- Open access: articles freely available online

- High visibility within the field

- Retaining the copyright to your article

Submit your next manuscript at $>$ springeropen.com 